\title{
Effect of new generation enzymes addition on the physical, viscoelastic and textural properties of traditional Mexican sweet bread
}

\author{
J.A. Barbosa-Ríos a , J. Castillón-Jardón a , A.Y. Guadarrama-Lezama a, J. Alvarez-Ramirez b , \\ M. Meraz ${ }^{\text {c }}$, H. Carrillo-Navas b, * \\ a Facultad de Química, Universidad Autónoma del Estado de México, Paseo Colón esq. Paseo Tollocan s/n, Col. Residencial Colón, Toluca, Estado de México, \\ 50120 Mexico \\ b Departamento de Ingeniería de Procesos e Hidráulica, Universidad Autónoma Metropolitana-Iztapalapa, San Rafael Atlixco No. 186, Col. Vicentina, Ciudad \\ de México, 09340 Mexico \\ ${ }^{\mathrm{c}}$ Departamento de Biotecnología, Universidad Autónoma Metropolitana-Iztapalapa, San Rafael Atlixco No. 186, Col. Vicentina, Ciudad de México, 09340 \\ Mexico
}

\section{A R T I C L E I N F O}

\section{Article history:}

Received 12 June 2017

Received in revised form

16 October 2017

Accepted 16 October 2017

Available online 27 October 2017

\section{Keywords:}

Traditional Mexican sweet bread

New generation enzymes

Viscoelastic properties

Texture properties

\begin{abstract}
A B S T R A C T
The effect of adding new generation enzymes $(0.25,0.5,0.75$, and $1.0 \% \mathrm{w} / \mathrm{w})$ on traditional Mexican sweet bread physical, viscoelastic (elastic and plastic work) and textural properties was studied. Physical properties as weight lost, pore uniformity, color, etc., improved with enzyme addition. Viscoelasticity properties were analyzed by uniaxial compression test under small strain, showing that the use of small enzyme fractions $(\sim 0.25-0.5 \% \mathrm{w} / \mathrm{w})$ are enough to enhance mechanical behavior (higher elastic work) and cohesiveness and resilience parameters after four storage days. This trend suggests a mechanism related to pore distribution and an equilibrium crust-crumb that lead to improved bread freshness over storage period. Overall, results indicated that relatively low enzyme concentrations can led to important improvements in the fabrication process of traditional Mexican sweet bread. The proposed enzyme concentrations are as small as $0.25-0.3 \% \mathrm{w} / \mathrm{w}$, corresponding to approximately half the percentage of the amount frequently used in industrial bread production.
\end{abstract}

() 2017 Elsevier Ltd. All rights reserved.

\section{Introduction}

Sweet bread is a traditional bakery product widely consumed in Mexico in breakfast and dinner. A huge amount of sweet bread is still fabricated by traditional methods, although high-scale industrialization has emerged as an option for reducing costs. Given that the fabrication of traditional sweet bread is based mostly on wheat flour, fat and sugar, its consumption is nowadays a treat for the population susceptible to metabolic syndrome. In this way, bread making industry has to adapt to Mexican eating habits, improving formulations, processes and adjusting the traditional products with innovative alternatives for the upcoming generations, without losing the essence of handmade products (Gómez et al., 2004; Tlapale-Valdivia et al., 2010).

The bread making industry has considered the incorporation of technological aids and additives, such as emulsifiers and enzymes

\footnotetext{
* Corresponding author

E-mail address: hcnavas@gmail.com (H. Carrillo-Navas).
}

to improve the physicochemical, thermal and rheological properties of doughs and breads (Haros et al., 2002). There exists a wide range of additives as ADA (azodicarboxinamide), potassium bromates, peroxides, etc., to improve dough and in general, bread fabrication. However, it has currently found that many of the additives could be harmful to human health, so the use of clean label compounds in bread products is a topic that concerns not only to population, but also to producers and researchers. Enzymes have been considered as good alternatives for use in baking processes. In this context, there are an extensive variety of enzymes depending on their effect and application (Hemalatha et al., 2010). Amylases in food processing have been intensively used; the commonly preferred are $\alpha$-amylases, maltogenic amylases and glucoamylases, or a blend of them from different origin (fungal or bacterial). Enzymes are used to accelerate starch degradation, preventing the structure collapse and offering a similar product with benefits in their control and processing (Gomes-Ruffi et al., 2012; Altuna et al., 2016). Nowadays, baking processes are increasingly using new generation enzymes (NGE), which are blends of several enzymes. The use of blends of enzymes in a same product allows extending 
product shelf-life and reducing ingredients concentration, such as sugar, syrups and yeast, lengthening the freshness and flavor of bread products throughout its storage time (Caballero et al., 2007). NGE are composed mainly by $\alpha$-amylases and maltogenic amylases, that enable to preserve external textural characteristics and improves viscoelastic properties on the internal network of the bread dough and in storage time, extending the crust and crumb freshness of sweet products. Specifically, the sweet bread systems, as dough leavened, behave different compared with batters or scratch formula commonly used in bakery products.

Endo-acting $\alpha$-amylases hydrolyze starch polymers and produce oligosaccharides, increasing the content of fermentable sugars that promotes uniform fermentation and indirectly, flavor intensification and modification of internal properties such as viscosity in the gelatinization step and the internal temperature of the dough (Goesaert et al., 2009). On the other hand, maltogenic amylases do not affect dough rheology at proofing time, but several studies report the behavior of this high temperature resistant enzyme, capable to hydrolyze glycosidic bonds releasing almost only $\alpha$ maltose during the baking period and contributing to a crumb with higher elasticity and softness during shelf-life (Dura and Rosell, 2016). The addition of NGE during bread making modify and enhance gluten rheology as well as bread quality, promoting an anti-staling effect and viscoelastic characteristics (Bollaín and Collar, 2004). With the inclusion of a viscoelasticity test (compression under small strain), this structural changes could maximize and demonstrate the real behavior of the bread from internal to external characteristics.

Therefore, the aim of this work was to evaluate the effect of different NGE concentration $(0 \%, 0.25 \%, 0.5 \%, 0.75 \%$, and $1.0 \% \mathrm{w} / \mathrm{w})$ on physical, viscoelastic and textural properties of traditional Mexican sweet bread (TMSB) as a function of storage time.

\section{Materials and methods}

\subsection{Materials}

Commercial wheat flour with $12.78 \% \mathrm{w} / \mathrm{w}$ protein, $6.05 \% \mathrm{w} / \mathrm{w}$ fat, $67.3 \% \mathrm{w} / \mathrm{w}$ carbohydrates, $5.59 \% \mathrm{w} / \mathrm{w}$ dietetic fiber was provided by Fábrica de Harinas Elizondo S.A. de C.V. (Mexico City, Mexico). Sugar, eggs and salt were obtained at a local supermarket (Walmart, Toluca, Mexico). Distilled water was used in all formulations. Dried baker's yeast was purchased from Nevada Brand (Safmex S.A. de C.V., Toluca, Mexico). Glycerol monostearate emulsifier (GMS-90), improver (Pristine) and commercial new generation enzymes (NGE) (Ultra Fresh) composed by $\alpha$-amylases and maltogenic amylases bacterial and fungal manufactured by Corbion Caravan (Kansas City, Missouri, USA) were used.

\subsection{Enzyme activities}

Enzyme activity was estimated using the method described by Rosell et al. (2001) and Haros et al. (2002). In particular, $\alpha$-amylase activity on the flour was measured using blocked $p$-nitrophenyl- $\alpha$ D-maltoheptaoside (BPNPG7, Megazyme International Ireland, Wicklow, Ireland) as assay substrate.

\subsection{Preparation of TMSB}

Traditional Mexican sweet bread (TMSB) formulation was based on $250 \mathrm{~g}$ of wheat flour, with water (55\%), sugar (10\%), whole egg (10\%), dried baker's yeast (2.5\%), emulsifier (2.0\%), salt (1.0\%), improver $(0.5 \%)$ and different concentrations of NGE $(0 \%, 0.25 \%$, $0.50 \%, 0.75 \%$, and $1.0 \% \mathrm{w} / \mathrm{w}$ ). The enzyme activity as a function of the NGE concentration is exhibited in Fig. S1, showing a linear trend with increasing enzyme activity as NGE concentration increased. The non-addition of shortening and the reduction of sugar content in the treatments proposed in this study were based on preliminary results (data not shown). The wheat flour, sugar, dried baker's yeast, salt, improver, and different concentrations of NGE were mixed in a Laboratory Spiral Mixer KitchenAid model 5K45SSWH (KitchenAid, Michigan, USA) for $4 \mathrm{~min}$ at low speed with a flat whisk and for 4 min at high speed with a spiral dough hook. Egg and water were mixed previously during $1 \mathrm{~min}$, keeping temperature at $25^{\circ} \mathrm{C}$ and were incorporated to the mix at the end of the low speed period. Emulsifier was added at the end of the high-speed period and was mixed afterwards for $3 \mathrm{~min}$ at medium speed. The bread dough was divided and molded in pieces of $70.0 \mathrm{~g}$ and compressed. Bread dough formulations were proofed for $60 \mathrm{~min}$ at $30{ }^{\circ} \mathrm{C}$ and $85 \%$ relative humidity in a proofing chamber. Dough formulations were put into a pre-heated system $\left(180{ }^{\circ} \mathrm{C}\right.$ and $10 \%$ relative humidity for $15 \mathrm{~min}$ ) automatically controlled static convection oven (Rational AG, Landsberg, Germany). Breads were withdrawn from the oven, and cooled during $120 \mathrm{~min}$ at $25^{\circ} \mathrm{C}$, and placed in an airtight plastic container until analysis. As reference, bread formulations were coded as $\mathrm{B}_{0}, \mathrm{~B}_{0.25}, \mathrm{~B}_{0.50}, \mathrm{~B}_{0.75}$ and $\mathrm{B}_{1.0}$ for dough containing $0 \%$ (control), $0.25 \%, 0.50 \%, 0.75 \%$ and $1.0 \% \mathrm{w} / \mathrm{w}$ of NGE, respectively.

\subsection{Baking time curves of TMSB}

The temperatures at the center of TMSB was monitored every $1 \mathrm{~min}$ by a thermocouple during bread making process (15 min) with the manual baking mode using an automatically controlled static convection oven (Rational AG, Landsberg, Germany).

\subsection{Crumb porosity of TMSB}

The sliced TMSB crumb structure was analyzed in terms of porosity using an ImageJ software version 1.47 (National Institutes of Health, USA) and images were captured with a Sony Cyber-shot DSC-HX60 digital camera (Sony, Tokio, Japan). In the first step of analysis, calibration of pixel measurement to mm-based unit was accomplished by digitizing and placing a ruler when the bread slice was captured ( $1 \mathrm{~mm}$ equivalent to 12 pixels). Afterwards, the image was converted to 8-bit grey level. Finally, a thresholding procedure was applied to identify pores. Values determined for each slice of bread (with a thickness of $20 \mathrm{~mm}$ ) were number of pores, mean pore area and standard deviation (SD) of the mean pore area.

\subsection{Physical parameters of TMSB}

Weight loss of TMSB was determined at $25{ }^{\circ} \mathrm{C}$ using an Ohaus electronic weighing balance model AP210 (Ohaus Corporation, New Jersey, USA) and was measured as the difference between the weight of the dough and the weight of the bread after baking. Volume of bread loaves $\left(\mathrm{cm}^{3}\right)$ were determined by rapeseed displacement according to the 10-05 method (AACC, 2000). A whole piece of bread was placed in a recipient containing millet seeds. The seeds displaced by the bread were collected and their volume measured. Bread crust color was assessed using a Chromameter model CR-400 (Minolta Company, Osaka, Japan), calibrated with a white reference plate which is the standard for reflectiveness. Color parameters were expressed as $\mathrm{L}^{*}$ (whiteness or brightness/darkness), a* (redness/greenness) and b* (yellowness/ blueness).

\subsection{Viscoelastic properties of TMSB}

Viscoelastic properties of TMSB formulations during storage time $(0,2$, and 4 days) were evaluated by a compression test under 
small strain using a TA.XT2 Plus texture analyzer (Texture Technologies, New York, USA/Stable Micro Systems Ltd., Surrey, UK) provided with an acrylic probe (10 $\mathrm{mm}$ in diameter, model SMS P/ $1 \mathrm{KS}$ ) and following the method reported by Ponce-García et al. (2017), modifying strain compression to 5.0\%. Briefly, each bread formulation was placed between two parallel plates with the creases side down. The compression work was determined from the loading-unloading curve.

The viscoelastic properties evaluated for bread formulations in this study were total work $\left(W_{t}\right)$, elastic work $\left(W_{e}\right)$, plastic work $\left(W_{p}\right)$, degree of elasticity $(D E)$ and degree of plasticity $(D P)$. The area under the loading curve shows the total work performed by the loading device during the compression of the bread. Elastic work was deduced from the area under the unloading curve and the energy absorbed by the plastic work, which was the difference between the total and elastic work $\left(W_{p}=W_{t}-W_{e}\right)$. The ratio of $W_{e}$ to $W_{t}$ when a bread formulation is loaded and then unloaded was the degree of elasticity $(D E)$ expressed as percentage, the same case applies for degree of plasticity $(D P)$, using $W_{p}$ instead of $W_{e}$.

\subsection{Texture profile analysis (TPA) of TMSB}

Texture profile analysis of TMSB was determined using a TA.XT2 Plus texture analyzer (Texture Technologies, New York, USA/Stable Micro Systems Ltd., Surrey, UK) provided with a $20 \mathrm{~mm}$ diameter probe aluminum (SMS P/20) and the strain applied was 75\%. TPA was carried out and force, resilience and cohesiveness were the main factors evaluated in all bread formulations during storage time $(0,2$, and 4 days).

\subsection{Sensory analysis of TMSB}

Sensory analysis of TMSB was conducted by 30 panelists (15 men and 15 women, mean age: 22 years, range: $20-23$ years) and the session was held at the Laboratory of Sensory Analysis of Food Chemistry Department (Autonomous University of the State of Mexico). Appearance, color of crust and crumb, texture, and overall taste were considered as sensory attributes using a scale from 0 to 10 , with 10 as the highest score. The training and selection of panelists were conducted in terms of texture recognition, color differences, and taste attributes. The selected panelists were able to give repeatable and reliable scores. Samples were coded, served, and evaluated in random order by duplicate for all bread formulations at 0 and 4 days. Before the sensory evaluation, TMSB were maintained at room temperature for 30-60 min after baking, samples were cut into $2.0 \mathrm{~cm}$ thick slices and divided in 4 smaller pieces. The final scores of each attribute are presented as the mean value of the results from the 30 panelists.

\subsection{Experimental design and statistical analyses}

All experiments were performed in triplicate samples and values are expressed as mean values \pm SD. Statistical analysis was performed with Statistical JMP software version 5.0.1.2 (SAS Institute Inc., North Carolina, USA). An analysis of one-way variance (ANOVA) was performed on the data gathered from the different evaluations, with a $\mathrm{P} \leq 0.05$ significance level. Tukey's test was used to compare mean values between treatments.

\section{Results and discussion}

\subsection{Baking time curves of TMSB}

Baking time curves as function of internal temperature are shown in Fig. 1. The maximum internal temperature in the bread

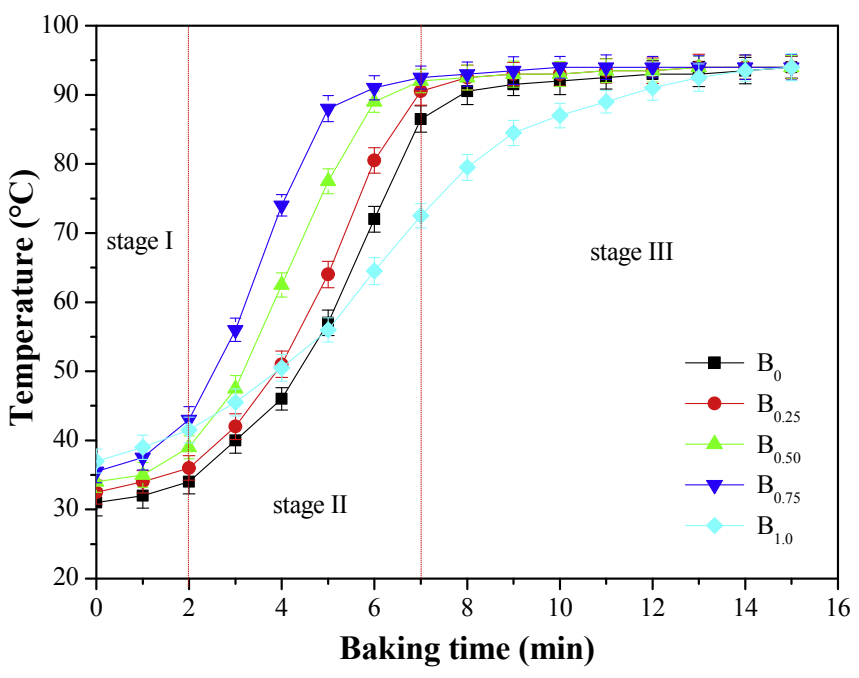

Fig. 1. Baking time curves of the different traditional Mexican sweet bread (TMSB) formulations.

making process for all formulations of traditional Mexican sweet bread (TMSB) was $\sim 94{ }^{\circ} \mathrm{C}$. As the concentration of the new generation enzymes (NGE) increased, the maximum internal temperature of bread presented shorter baking times ( $>\mathrm{min})$, with exception of $\mathrm{B}_{1.0}$, which reached the maximum internal temperature at a higher baking time ( $13 \mathrm{~min})$. This behavior can be attributed to the two types of enzymes ( $\alpha$-amylases and maltogenic amylases) contained in the NGE acting at different baking stages. Once the temperature during bread making process reached $\sim 54.4{ }^{\circ} \mathrm{C}$, yeast activity stopped and starch gelatinization begins (Charley, 2012). Thus, $\alpha$-amylases started to hydrolyze $\alpha-1,4$ and $\alpha$ 1, 6 bonds of the gelatinized starch to produce small dextrins units. Relatively low $\alpha$-amylase content incorporated within the NGE led to low dextrins and $\mathrm{CO}_{2}$ production. In contrast, high degradation of gelatinized starch will be produced caused by high concentrations of $\alpha$-amylase in dough formulations. In turn, this led to reduced dextrins concentration, and subsequently to prolong baking times (van Oort, 2010). Once the activity of the $\alpha$-amylases stopped, their action on specific sites on the starch, maltogenic amylases (are most active between 60 and $70{ }^{\circ} \mathrm{C}$ ), limits the retrogradation of the amylopectin (that was lixiviated during gelatinization process). Also, the activity of the $\alpha$-amylases had a positive effect on water distribution, conferring anti-staling effect. Linear amylose can be easily accessible to the active site than amylopectin, resulting in a selective degradation of amylose (Goesaert et al., 2009; Li et al., 2014). Hence, the gelatinization process and the time at which the bread reached the maximum internal temperature are directly related. If gelatinization of the starch is carried out at lower temperatures, longer times to build up bread structure are required (Doğan, 2003). When internal temperature during the baking process rises rapidly, between 90 and $94{ }^{\circ} \mathrm{C}$, the enzymes are inactivated causing a softening of the dough and crumb, modifying bread texture (Charley, 2012).

Baking time curves can be divided into three stages (Fig. 1). Stage I (adjustment period) is characterized by a tiny change in the dough temperature and a rapid step-up during $\sim 2$ min. Water diffuses from dough bulk to the surface where is removed. In turn, this effect promotes a slower loss of produced gas, resulting in the formation of many pores and a cell interconnection of the dough (Gan et al., 1995). Stage II (constant loss of water period) can be described as a step where a fast increase in temperature is achieved. Dough water is evaporated at nearly a constant rate as the 
vapor pressure becomes equal to the vapor pressure of water. Here, the bread crust begins to form (Grenier et al., 2010). Finally, Stage III is characterized by an asymptotic increase in temperature $\left(94^{\circ} \mathrm{C}\right)$, showing a controlled baking period that depends of water amount bounded to the dough, and the internal movement of the water. Furthermore, heating rate can be estimated from the linear region of rapidly increasing temperature between 40 and $90{ }^{\circ} \mathrm{C}$. In this way, $\mathrm{B}_{0.75}$ has the highest heating rate $\left(11.2^{\circ} \mathrm{C} / \mathrm{min}\right)$, while $\mathrm{B}_{1.0}$ has the lowest heating rate $\left(6.2^{\circ} \mathrm{C} / \mathrm{min}\right)$ (see Table 1$)$. In addition, a baking constant temperature was observed for all bread formulations in the last stage, with the exception of the $B_{1.0}$. A similar behavior was reported by Besbes et al. (2013), whom analyzed the thermal profiles on the cellular structure of bread baked at $220^{\circ} \mathrm{C}$ and $240{ }^{\circ} \mathrm{C}$, corresponding to heating rates of 6.11 and $7.39{ }^{\circ} \mathrm{C} / \mathrm{min}$, respectively.

\subsection{Crumb porosity of TMSB}

Fig. 2 presents crumb porosity images of the different bread formulations. Images showed in the center and right panels are in grayscale and binarized modes, respectively. It can be observed the heterogeneous structure which is caused by the pore size structure formed during baking process and $\mathrm{CO}_{2}$ generation. Heterogeneity of the pore size increased with NGE concentration, i.e., $B_{1.0}$ showed a dense and less uniform crumb structure (Fig. 2e). In this sense, the overall crumb structure seems to be smaller when the NGE was decreased, producing higher pore homogeneity (Fig. 2b). As the NGE concentration increased, the excessive production of dextrins as resource of fermentable sugars induced a pore structure with similar characteristics to $\mathrm{B}_{0}$, although without an acceptable water content $(54-58 \% \mathrm{w} / \mathrm{w}$ of total weight formulation). For water contents higher than $54-58 \%(\mathrm{w} / \mathrm{w})$, the network begin to broke down and undergo deformation from inside to outside. The smallest pores became associated and joined to others, giving rise to the formation of bigger pores (Zghal et al., 2001; Tlapale-Valdivia et al., 2010).

In the binarized images (Fig. 2), the black regular regions (bubbles) of the TMSB in the formulations from $\mathrm{B}_{0}$ and $\mathrm{B}_{0.25}$ (Fig. 2a and $b$ ) were located in the center of the crumb. In contrast, the black regular regions of the TMSB from $\mathrm{B}_{0.5}, \mathrm{~B}_{0.75}$ and $\mathrm{B}_{1.0}$ (Fig. $2 \mathrm{c}$ to e) are close to the crust, becoming a more fragile structure with respect to other formulated breads. In fact, these formed bubbles are smallest pores that during dough fermentation process tend to expand. Small pores tend to coalesce to form larger bubbles and probably migrate close to the crust, having an adverse effect on the stability of the bread structure. Zhang and Datta (2006) observed that in binarized images of bread formulations, pores interconnected in the crumb (the black region) are larger, while in the crust the pores tend to be smaller.

The mean pore area for all TMSB ranged between 0.13 and $8.5 \mathrm{~mm}^{2}$ (data not shown), presenting the larger number of pores in the smallest area $\left(0.13 \mathrm{~mm}^{2}\right)$. According to Jha et al. (2017), the pore size distribution showed a non-Gaussian shape and the average size of majority cells was smaller. In this study, all formulations presented a reduced number of pores when increased mean pore area (i.e., smaller number of larger bubbles, except $B_{1.0}$ ). The minimum and maximum values of the number of pores (603 and 846, respectively) in the smaller area $\left(0.13 \mathrm{~mm}^{2}\right)$ were observed for $\mathrm{B}_{0}$ and $\mathrm{B}_{0.25}$ formulations. In the same way, in the highest mean pore area value $\left(8.5 \mathrm{~mm}^{2}\right), \mathrm{B}_{0.25}$ and $\mathrm{B}_{1.0}$ presented the minimum (5 pores) and maximum ( 120 pores) pore numbers. Therefore, $B_{0.25}$ formulation developed better characteristics, improving $\mathrm{CO}_{2}$ distribution during mixing time and fermentation process, due maybe to the homogeneity of the bubbles formed about the crumb structure.

Table 1 presents the mean pore area and the pore uniformity obtained by image analysis using an Image software version 1.47 (National Institutes of Health, USA). The mean pore area showed important increase as the NGE concentration was increased, with values ranging from 0.26 to $3.11 \mathrm{~mm}^{2}$ and $1.23 \mathrm{~mm}^{2}$ for $\mathrm{B}_{0}$. Pore uniformity (Table 1) showed that $B_{0.25}$ is the TMSB with lower standard deviation (SD), resulting in a minor heterogeneity of mean pore area in the crumb. Schoenlechner et al. (2013) studied the effect of single and combined enzymes (transglutaminase and xylanase) addition in bread, finding that a desirable range of mean pore area and pore uniformity in bread are $5.0-7.6 \mathrm{~mm}^{2}$ and $6.7-10.1 \mathrm{~mm}^{2}$, respectively.

\subsection{Physical parameters of TMSB}

Weight loss of TMSB presented a decrease as the NGE concentration increased, except for $B_{1.0}$ formulation, which showed a weight loss value similar to $\mathrm{B}_{0}$ (Table 1 ). However, the structure of $\mathrm{B}_{1.0}$ collapsed and became denser. Produced $\mathrm{CO}_{2}$ migrated from the crumb to the crust, resulting in a higher moisture loss compared with other formulations. This effect is correlated to the baking time curves (Fig. 1), in the sense that the smaller weight loss occurred when the bread crust formed faster, i.e., as the heating rate of the baking process was fastest (Table 1 ), the water loss in bread structure was slower. It is apparent that bread crust acted as a barrier for water migration from the bread bulk. During and after bread baking process, the crust formation affected the amount of moisture evaporated from dough, preventing the moisture migration to the exterior and reducing crumb staling. Bubbles present in the bread migrated from the internal structure to the crust and an excessive amount of smaller bubbles of $\mathrm{CO}_{2}$ formed and later exploded. The weakened pore spaces allowed almost all water to migrate from crumb to crust, which in turn led to water redistribution in equilibrium with vapor phase (Primo-Martín et al., 2006; Mohd Jusoh et al., 2009).

The volume $\left(\mathrm{cm}^{3}\right)$ of the TMSB formulations is exhibited in Table 1 . The volume ranged from 238.60 to $270.50 \mathrm{~cm}^{3}$, the lowest being $\mathrm{B}_{0}$ and the highest corresponding to $\mathrm{B}_{0.75}$. As the concentration of the NGE increased in the TMSB, the volume of bread was higher, with exception of $\mathrm{B}_{1.0}$. This behavior can be attributed to the presence of $\alpha$-amylases in NGE composition, which broke down

Table 1

Heating rates from baking time curves and physical properties of traditional Mexican sweet bread formulations.

\begin{tabular}{|c|c|c|c|c|c|c|c|c|}
\hline \multirow[t]{2}{*}{ Sample } & \multirow{2}{*}{$\begin{array}{l}\text { Heating rate } \\
\left({ }^{\circ} \mathrm{C} / \mathrm{min}\right)\end{array}$} & \multirow{2}{*}{$\begin{array}{l}\text { Mean pore area } \\
\left(\mathrm{mm}^{2}\right)\end{array}$} & \multirow{2}{*}{$\begin{array}{l}\text { Pore uniformity } \\
\text { (SD of pore area) }\end{array}$} & \multirow{2}{*}{$\begin{array}{l}\text { Weight loss } \\
(\mathrm{g})\end{array}$} & \multirow{2}{*}{$\begin{array}{l}\text { Volume } \\
\left(\mathrm{cm}^{3}\right)\end{array}$} & \multicolumn{3}{|c|}{ Color Parameters } \\
\hline & & & & & & $\mathrm{L}^{*}$ & $a^{*}$ & $\mathrm{~b}^{*}$ \\
\hline $\mathrm{B}_{0}$ & $10.20 \pm 0.30^{\mathrm{b}}$ & $1.23 \pm 0.24^{\mathrm{b}, \mathrm{c}}$ & $2.61 \pm 0.31^{b}$ & $16.18 \pm 0.34^{\mathrm{c}}$ & $238.60 \pm 4.77^{\mathrm{a}}$ & $45.07 \pm 1.31^{\mathrm{c}}$ & $10.58 \pm 0.18^{a}$ & $35.30 \pm 0.77^{c}$ \\
\hline $\mathrm{B}_{0.25}$ & $10.50 \pm 0.20^{b, c}$ & $0.26 \pm 0.04^{\mathrm{a}}$ & $0.33 \pm 0.02^{\mathrm{a}}$ & $15.56 \pm 0.26^{\mathrm{b}, \mathrm{c}}$ & $243.20 \pm 6.08^{\mathrm{a}, \mathrm{b}}$ & $41.26 \pm 1.14^{\mathrm{b}}$ & $11.05 \pm 0.24^{\mathrm{a}}$ & $34.54 \pm 0.71^{c}$ \\
\hline $\mathrm{B}_{0.50}$ & $10.90 \pm 0.10^{c, d}$ & $0.82 \pm 0.17^{\mathrm{a}, \mathrm{b}}$ & $0.96 \pm 0.10^{\mathrm{a}}$ & $15.08 \pm 0.18^{b}$ & $261.20 \pm 7.84^{\mathrm{b}, \mathrm{c}}$ & $40.71 \pm 1.08^{b}$ & $12.97 \pm 0.30^{b}$ & $33.90 \pm 0.65^{\mathrm{b}, \mathrm{c}}$ \\
\hline$B_{0.75}$ & $11.20 \pm 0.30^{\mathrm{d}}$ & $2.05 \pm 0.35^{c}$ & $4.18 \pm 0.63^{c}$ & $14.32 \pm 0.15^{\mathrm{a}}$ & $270.50 \pm 6.55^{c}$ & $39.97 \pm 0.99^{b}$ & $14.14 \pm 0.35^{c}$ & $32.40 \pm 0.61^{\mathrm{a}, \mathrm{b}}$ \\
\hline $\mathrm{B}_{1.0}$ & $6.20 \pm 0.20^{\mathrm{a}}$ & $3.11 \pm 0.62^{\mathrm{d}}$ & $5.09 \pm 0.92^{c}$ & $16.26 \pm 0.38^{c}$ & $265.20 \pm 8.03^{c}$ & $34.13 \pm 0.92^{\mathrm{a}}$ & $15.02 \pm 0.37^{\mathrm{d}}$ & $31.67 \pm 0.57^{\mathrm{a}}$ \\
\hline
\end{tabular}

${ }^{a}$ Values are means \pm standard error, of three replicates. Superscripts with different letters in same column indicate significant differences (P $\left.\leq 0.05\right)$. 

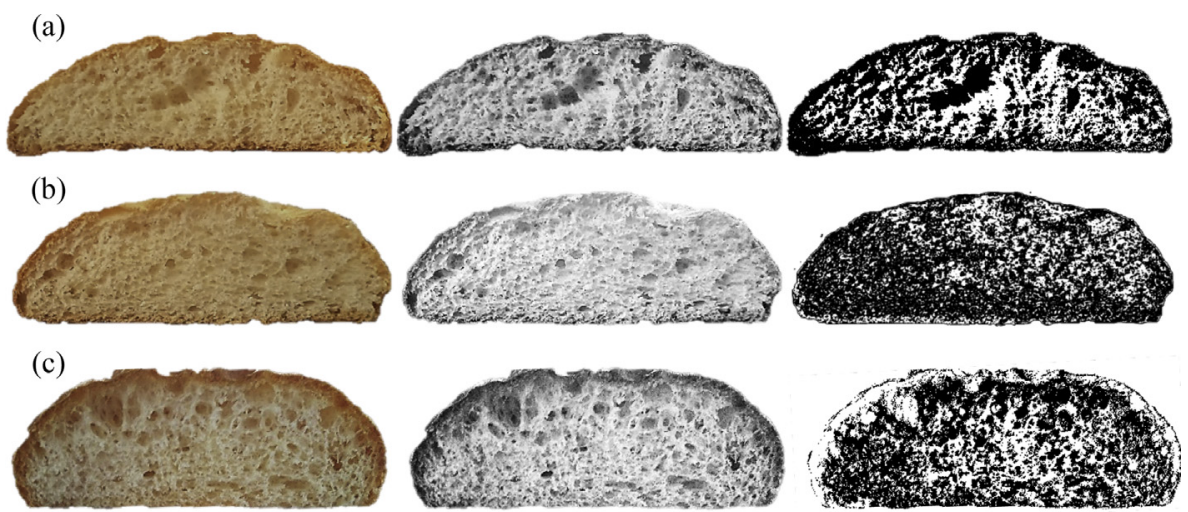

(d)
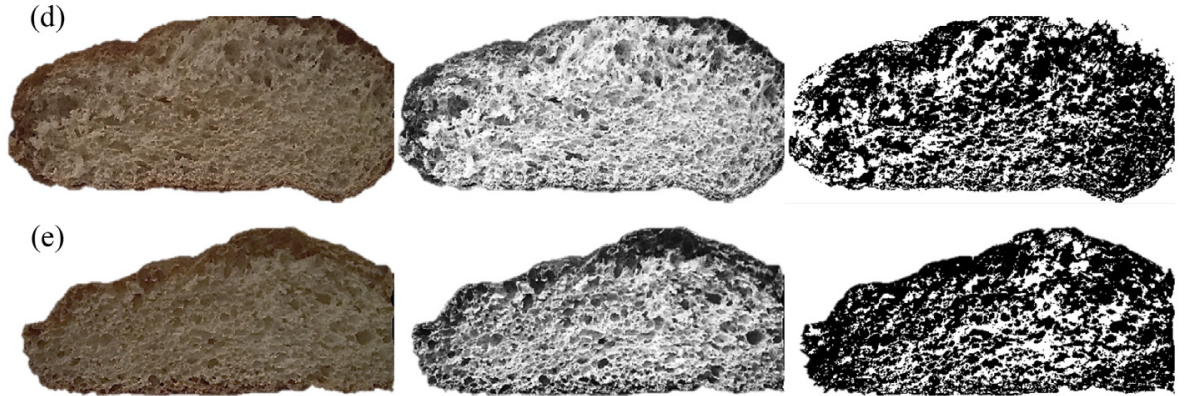

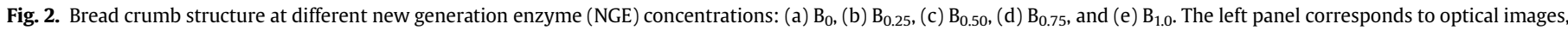
while in the center and right panel are images in grayscale and binarized.

specific bonds in starch and supply fermentable sugars for yeast growth and gas production mainly before the baking process. However, if these fermentable sugars saturate the system (as in $B_{1.0}$ ), the fermentation process can be inhibited because of the reduction of carbon dioxide production, affecting the final volume of bread loaf (Gomes-Ruffi et al., 2012).

Differences in color parameters were observed between $\mathrm{B}_{0}$ and the breads containing NGE (Table 1). The crust color browning increased by Maillard reactions between proteins and reducing sugars when amounts of NGE increased. The lightness $\left(\mathrm{L}^{*}\right)$ and yellowish $\left(b^{*}\right)$ parameters of TMSB decreased with the addition of NGE and values of redness $\left(a^{*}\right)$ were higher when NGE increased. This behavior could be attributed to the higher availability of dextrins produced by NGE addition. The absence of shortening in formulations and a saturation of different dextrins tend to caramelize at baking temperatures, conferring a saturated reddish color and a slightly yellowish appearance to the TMSB (Purlis and Salvadori, 2009).

\subsection{Viscoelastic properties of TMSB}

Table 2 presents the parameters of viscoelastic properties such as total, elastic and plastic work for all TMSB formulations. Total work $\left(W_{t}\right)$ and plastic work $\left(W_{p}\right)$ were smaller when NGE concentration increased in the bread. Besides, increase in NGE concentration had a positive effect in $W_{e}$, indicating that its incorporation enhanced the softness in the bread microstructure due to released dextrins by enzyme activity and strengthening of the gluten network (Mathewson, 1998). However, $W_{e}$ decreased in $B_{1.0}$ due to fragility of the crust. This effect could be linked to the larger and less uniform bubbles that migrated from the center of crumb to the crust. Overall, the incorporation of NGE modified the physical properties of TMSB during storage time retarding staling, improving distribution of proteins and hydrated sugars in the gluten network (Giannone et al., 2016), as well as gas retention and smoothly formation of bubbles. This behavior was possible by a joint action of the $\alpha$-amylases and maltogenic amylases, contained in NGE (Gomes-Ruffi et al., 2012).

During storage time, $W_{t}$ and $W_{p}$ increased and $W_{e}$ decreased, although $\mathrm{B}_{0.25}$ presented a higher $W_{e}$ value than other NGE concentrations along shelf-life. This effect could be related to an improved balance of dextrins in the gluten network without affecting the formation of the crumb and the total bread structure. $\mathrm{B}_{1.0}$ formulation was an exception with respect to $W_{e}$ of the whole breads, because $W_{t}$ showed a lesser value than others, caused by the collapsed structure.

The force-deformation curves showed important differences linked to differences in the crust-crumb structure. Differences were attributed to the NGE concentration added and the storage time. Formulation $\mathrm{B}_{0.25}$ at day 0 and 4 (Fig. $3 \mathrm{a}$ and c) required a similar compression force, but presented higher values of $W_{p}$ and $W_{e}$ as compared to $\mathrm{B}_{1.0}$ formulation at the same storage days (Fig. $3 \mathrm{~b}$ and d). During storage time, compression force increased and $W_{e}$ decreased for all TSMB formulations, an effect that can be due to loss of moisture (10-15\%) and staling mechanisms. Additionally, $\mathrm{B}_{1.0}$ at day 0 (Fig. $3 \mathrm{~b}$ ) showed slight surface ruptures in the compression stage, which could be caused by the larger amount of different size bubbles formed near the crust during the bread making process. At day 4 (Fig. 3d), the small bubbles previously formed in $\mathrm{B}_{1.0}$ formulation were aggregated in a way that the smaller ones were united to larger ones, leading to a bread with reduced uniformity. Peak area of force-deformation curves expresses the total required energy during bread compression at an specific percentage (5.0\%) and is related to the internal forces of the dough (Ponce-García et al., 2017).

\subsection{Texture profile analysis (TPA) of TMSB}

The results of texture profile analysis expressed as force, resilience and cohesiveness parameters during storage time of TMSB 
Table 2

Viscoelastic properties of TMSB formulations during the storage time.

\begin{tabular}{|c|c|c|c|c|c|c|}
\hline Sample & Storage time (days) & $W_{t}(\mathrm{~N} \mathrm{~mm})$ & $W_{e}(\mathrm{~N} \mathrm{~mm})$ & $W_{p}(\mathrm{~N} \mathrm{~mm})$ & $D E(\%)$ & $D P(\%)$ \\
\hline \multirow[t]{3}{*}{$\mathrm{B}_{0}$} & 0 & $1.33 \pm 0.05^{\mathrm{c}, \mathrm{A}}$ & $0.36 \pm 0.01^{\mathrm{a}, \mathrm{B}}$ & $0.97 \pm 0.03^{\mathrm{d}, \mathrm{A}}$ & $27.07 \pm 0.95^{\mathrm{a}, \mathrm{C}}$ & $72.93 \pm 2.55^{\mathrm{d}, \mathrm{A}}$ \\
\hline & 2 & $1.49 \pm 0.06^{\mathrm{c}, \mathrm{B}}$ & $0.33 \pm 0.01^{\mathrm{a}, \mathrm{b}, \mathrm{B}}$ & $1.16 \pm 0.04^{\mathrm{c}, \mathrm{B}}$ & $22.15 \pm 0.78^{\mathrm{a}, \mathrm{B}}$ & $77.85 \pm 2.72^{\mathrm{c}, \mathrm{A}, \mathrm{B}}$ \\
\hline & 4 & $1.58 \pm 0.07^{\mathrm{c}, \mathrm{B}}$ & $0.27 \pm 0.02^{\mathrm{a}, \mathrm{A}}$ & $1.31 \pm 0.04^{\mathrm{c}, \mathrm{C}}$ & $17.09 \pm 0.60^{\mathrm{a}, \mathrm{A}}$ & $82.91 \pm 2.90^{\mathrm{b}, \mathrm{B}}$ \\
\hline \multirow[t]{3}{*}{$\mathrm{B}_{0.25}$} & 0 & $0.92 \pm 0.02^{\mathrm{b}, \mathrm{A}}$ & $0.39 \pm 0.01^{\mathrm{a}, \mathrm{b}, \mathrm{B}}$ & $0.53 \pm 0.01^{\mathrm{c}, \mathrm{A}}$ & $42.39 \pm 0.85^{\mathrm{b}, \mathrm{C}}$ & $57.61 \pm 1.15^{\mathrm{c}, \mathrm{A}}$ \\
\hline & 2 & $0.96 \pm 0.03^{\mathrm{b}, \mathrm{A}, \mathrm{B}}$ & $0.35 \pm 0.01^{\mathrm{a}, \mathrm{b}, \mathrm{A}}$ & $0.61 \pm 0.02^{\mathrm{b}, \mathrm{B}}$ & $36.46 \pm 0.73^{\mathrm{b}, \mathrm{B}}$ & $63.54 \pm 1.27^{\mathrm{b}, \mathrm{B}}$ \\
\hline & 4 & $1.00 \pm 0.04^{\mathrm{b}, \mathrm{B}}$ & $0.33 \pm 0.01^{\mathrm{b}, \mathrm{c}, \mathrm{A}}$ & $0.67 \pm 0.02^{b, c}$ & $33.00 \pm 0.66^{\mathrm{b}, \mathrm{A}}$ & $67.00 \pm 1.34^{\mathrm{a}, \mathrm{C}}$ \\
\hline \multirow[t]{3}{*}{$\mathrm{B}_{0.50}$} & 0 & $0.87 \pm 0.02^{\mathrm{b}, \mathrm{c}, \mathrm{A}}$ & $0.42 \pm 0.02^{\mathrm{b}, \mathrm{B}}$ & $0.45 \pm 0.01^{\mathrm{b}, \mathrm{A}}$ & $48.28 \pm 1.21^{\mathrm{c}, \mathrm{C}}$ & $51.72 \pm 1.29^{\mathrm{b}, \mathrm{A}}$ \\
\hline & 2 & $0.90 \pm 0.03^{\mathrm{a}, \mathrm{b}, \mathrm{A}}$ & $0.36 \pm 0.01^{\mathrm{b}, \mathrm{A}}$ & $0.54 \pm 0.02^{\mathrm{a}, \mathrm{b}, \mathrm{B}}$ & $40.00 \pm 1.00^{\mathrm{c}, \mathrm{d}, \mathrm{B}}$ & $60.00 \pm 1.50^{\mathrm{a}, \mathrm{b}, \mathrm{B}}$ \\
\hline & 4 & $0.97 \pm 0.03^{\mathrm{b}, \mathrm{B}}$ & $0.34 \pm 0.01^{\mathrm{c}, \mathrm{A}}$ & $0.63 \pm 0.02^{\mathrm{b}, \mathrm{C}}$ & $35.05 \pm 0.88^{\mathrm{b}, \mathrm{c}, \mathrm{A}}$ & $64.95 \pm 1.62^{\mathrm{a}, \mathrm{C}}$ \\
\hline \multirow[t]{3}{*}{$\mathrm{B}_{0.75}$} & 0 & $0.85 \pm 0.02^{\mathrm{b}, \mathrm{A}}$ & $0.42 \pm 0.01^{\mathrm{b}, \mathrm{B}}$ & $0.43 \pm 0.02^{\mathrm{b}, \mathrm{A}}$ & $49.41 \pm 1.48^{\mathrm{c}, \mathrm{C}}$ & $50.59 \pm 1.52^{\mathrm{b}, \mathrm{A}}$ \\
\hline & 2 & $0.88 \pm 0.02^{\mathrm{a}, \mathrm{b}, \mathrm{A}}$ & $0.37 \pm 0.01^{\mathrm{b}, \mathrm{A}}$ & $0.51 \pm 0.02^{\mathrm{a}, \mathrm{B}}$ & $42.05 \pm 1.26^{\mathrm{d}, \mathrm{B}}$ & $57.95 \pm 1.74^{\mathrm{a}, \mathrm{B}}$ \\
\hline & 4 & $0.95 \pm 0.03^{\mathrm{b}, \mathrm{B}}$ & $0.34 \pm 0.02^{\mathrm{c}, \mathrm{A}}$ & $0.61 \pm 0.03^{b, c}$ & $35.79 \pm 1.07^{\mathrm{c}, \mathrm{A}}$ & $64.21 \pm 1.93^{\mathrm{a}, \mathrm{C}}$ \\
\hline \multirow[t]{3}{*}{$\mathrm{B}_{1.0}$} & 0 & $0.66 \pm 0.03^{\mathrm{a}, \mathrm{A}}$ & $0.37 \pm 0.02^{\mathrm{a}, \mathrm{B}}$ & $0.29 \pm 0.02^{\mathrm{a}, \mathrm{A}}$ & $56.06 \pm 2.24^{\mathrm{d}, \mathrm{B}}$ & $43.94 \pm 1.76^{\mathrm{a}, \mathrm{A}}$ \\
\hline & 2 & $0.80 \pm 0.05^{\mathrm{a}, \mathrm{B}}$ & $0.31 \pm 0.03^{\mathrm{a}, \mathrm{A}, \mathrm{B}}$ & $0.49 \pm 0.03^{\mathrm{a}, \mathrm{B}}$ & $38.75 \pm 1.55^{\mathrm{b}, \mathrm{c}, \mathrm{A}}$ & $61.25 \pm 2.45^{\mathrm{a}, \mathrm{b}, \mathrm{B}}$ \\
\hline & 4 & $0.78 \pm 0.07^{\mathrm{a}, \mathrm{A}, \mathrm{B}}$ & $0.28 \pm 0.03^{\mathrm{a}, \mathrm{b}, \mathrm{A}}$ & $0.50 \pm 0.04^{\mathrm{a}, \mathrm{B}}$ & $35.90 \pm 1.44^{\mathrm{c}, \mathrm{A}}$ & $64.10 \pm 2.56^{\mathrm{a}, \mathrm{B}}$ \\
\hline
\end{tabular}

aNotation: $W_{t}$, total work; $W_{p}$, plastic work; $W_{e}$, elastic work; DP, degree of plasticity; DE, degree of elasticity.

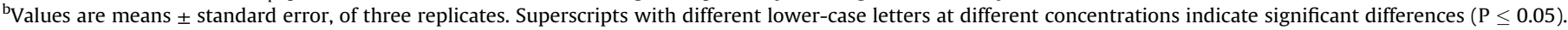
Superscripts with different capital letters at different storage time indicate significant differences $(P \leq 0.05)$.
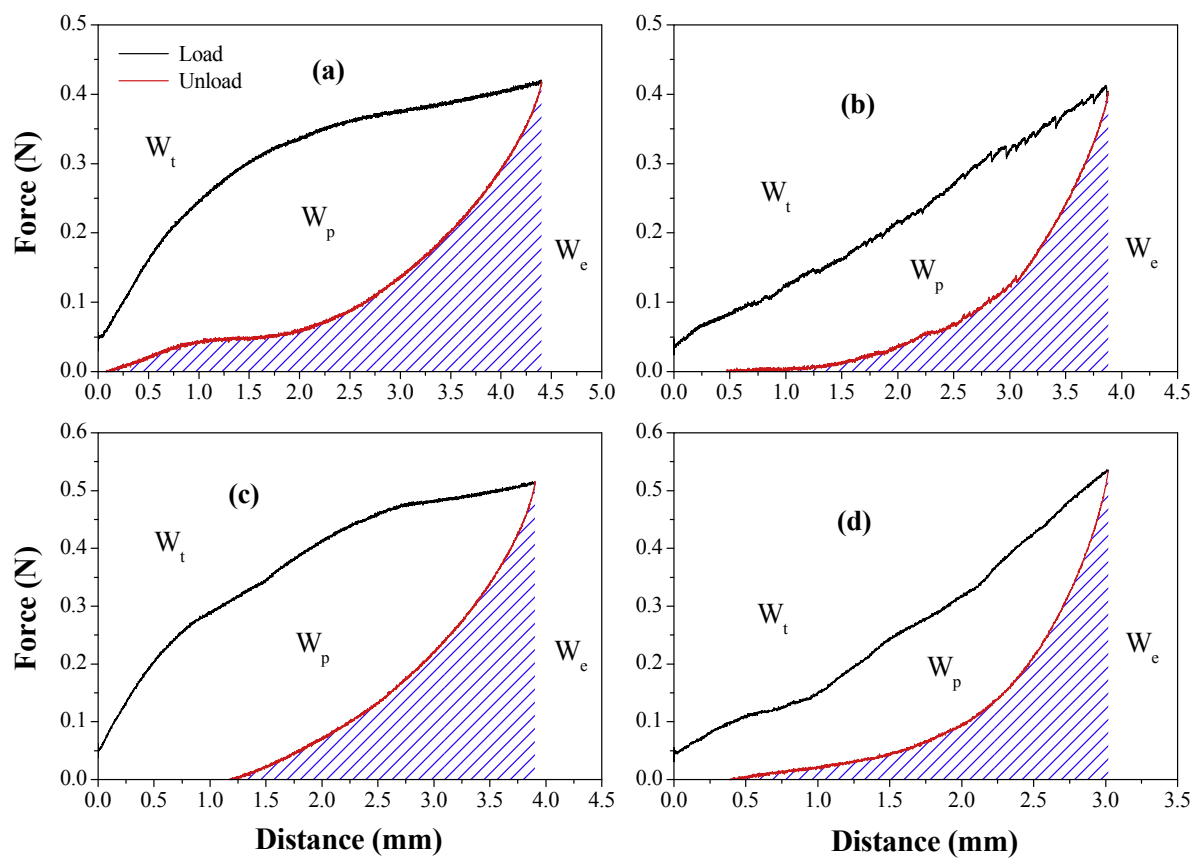

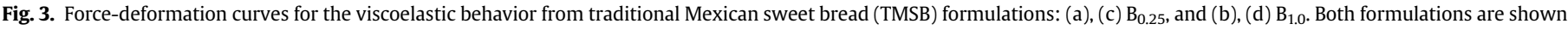
at 0 and 4 days, respectively.

are illustrated in Fig. 4. An increase in NGE concentration promoted a lower force of compression in the different bread formulations. On the other hand, throughout storage time, force in the compression stage was increased as caused by hardening of bread crust by retrogradation phenomena. At day 0 of storage time, compression force in bread was similar for all samples, presenting a slight decrease when the NGE concentration increased. As storage time increased, differences in force were more remarkable. $B_{1.0}$ was the formulation with less variation through the four days of storage, a behavior that can be attributed to the larger bubbles presented in the bread near the crust, which increased its fragility. Resilience is defined as the recovery rate from compression test. TMSB exhibited values of resilience in a range of $0.07-0.17$. The increase in NGE concentration in bread formulations caused higher resilience values (except $\mathrm{B}_{1.0}$, that presented similar values to $\mathrm{B}_{0}$ ), while all resilience values along storage time decreased due to bread staling.
$\mathrm{B}_{0}$ and $\mathrm{B}_{1.0}$ showed the lower resilience values. These results could be attributed to water loss during storage and water molecules migration to the crust. Similar results were reported by de la Hera et al. (2014), finding that resilience measurements are affected by the water content in bread. Cohesiveness expresses the cohesion of the material. Low cohesiveness indicates a structure more susceptible to crumble and fracture (Onyango et al., 2010). High cohesiveness values are desirable for industry scale producers and bread distributors. The addition of NGE had a positive effect on bread cohesiveness. However, storage time influenced cohesiveness values as storage time increased (i.e., cohesiveness of the TMSB decreased due to staling effect). Interestingly, cohesiveness of $B_{1.0}$ formulation deviated from such behavior. The addition of NGE decreased the cohesiveness due maybe to an excessive production of dextrins that caused a more fragile bread structure. Overall, cohesiveness and resilience parameters of TPA were directly 


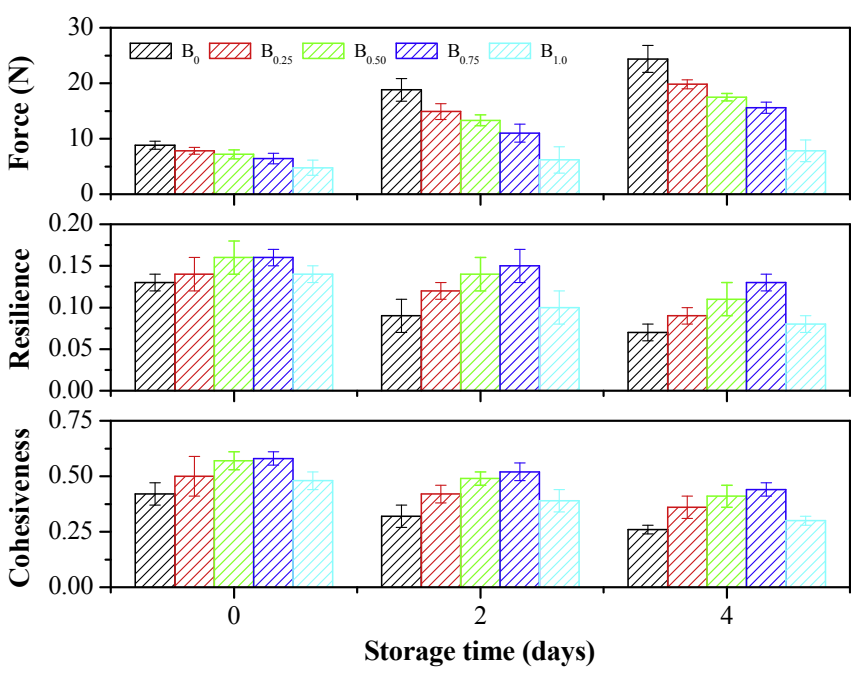

Fig. 4. Texture profile analysis parameters of the different traditional Mexican sweet bread (TMSB) formulations during storage time: (a) Force, (b) Resilience and (c) Cohesiveness.

correlated with addition of NGE and storage time, while force of compression presented an inverse contrary effect.

\subsection{Sensory analysis of TMSB}

Figure S2 in supplementary material displays sensory analysis of the different TMSB formulations at 0 and 4 days. $\mathrm{B}_{0.25}$ obtained a major preference in all parameters, followed by the $B_{0.50}$ formulation. The panelists scored higher the appearance of breads with uniform crumb structure. $\mathrm{B}_{0.50}$ and $\mathrm{B}_{1.0}$ presented lower values in the appearance score, due to bubbles formation near the crust in the bread and for the excessive brown color caused by Maillard reactions. This parameter is important for consumers because the crumb uniformity is related to quality in bakery products, a bigger pore area is considered as a low quality product. Crust and crumb color appreciation by the panel showed a preference for breads with lowest enzyme concentration because when the enzyme concentration increased, excessive production of dextrins conferred crust saturated redness colors and minor luminosity. Besides, panelists showed an inclination for $\mathrm{B}_{0.25}$ in texture and taste attributes because bread presented structures with good sponginess and consistency. Finally, after storage time panelists appreciated the $\mathrm{B}_{0.25}$ as a better quality consumption product.

\section{Conclusions}

In conclusion, the incorporation of relatively small amounts of NGE improved physical and textural properties of traditional sweet bread. Staling during storage time decreased as induced by a better distribution of pores within the bread structure, and to reduction of water loss due to more stable crust configuration. The joint action of the $\alpha$-amylases and maltogenic amylases enzymes offers advantages over the traditional leavening process since the action of these enzymes is more specific, acting at different phases of the baking process. In consequence, the bread exhibited good physical and textural properties, extending its freshness over more days. Overall, NGE is an accepted technology to be used in traditional bread products, extending its shelf life and being a good alternative to small businesses bread for cost reduction, with the use of less quantity of product as is usually required (lower than $0.5 \%$ ).

\section{Conflict of interest}

The authors declare no conflict of interest.

\section{Appendix A. Supplementary data}

Supplementary data related to this article can be found at https://doi.org/10.1016/j.jcs.2017.10.012.

\section{References}

Altuna, L., Ribotta, P.D., Tadini, C.C., 2016. Effect of a combination of enzymes on the fundamental rheological behavior of bread dough enriched with resistant starch. LWT-Food Sci. Technol. 73, 267-273.

American Association of Cereal Chemists, AACC, 2000. Approved Methods of the AACC. AACC International, Minnesota.

Besbes, E., Jury, V., Monteau, J.Y., Le Bail, A., 2013. Characterizing the cellular structure of bread crumb and crust as affected by heating rate using X-ray microtomography. J. Food Eng. 115 (3), 415-423.

Bollaín, C., Collar, C., 2004. Dough viscoelastic response of hydrocolloid/enzyme/ surfactant blends assessed by uni-and bi-axial extension measurements. Food Hydrocoll. 18 (3), 499-507.

Caballero, P.A., Gómez, M., Rosell, C.M., 2007. Improvement of dough rheology, bread quality and bread shelf-life by enzymes combination. J. Food Eng. 81 (1) 42-53.

Charley, H., 2012. Food Technology: Chemist and Physics Processes in Food Preparation, third ed. Limusa Editorial, Mexico.

de la Hera, E., Rosell, C.M., Gomez, M., 2014. Effect of water content and flour particle size on gluten-free bread quality and digestibility. Food Chem. 151, 526-531.

Doğan, İ.S., 2003. Effect of $\alpha$-amylases on dough properties during Turkish hearth bread production. Int. J. Food Sci. Technol. 38 (2), 209-216.

Dura, A., Rosell, C.M., 2016. Enzymes in baking. In: Ray, R.C., Rosell, C.M. (Eds.), Microbial Enzyme Technology in Food Applications. CRC Press, Florida, pp. 295-314.

Gan, Z., Ellis, P.R., Schofield, J.D., 1995. Gas cell stabilization and gas retention in wheat bread dough. J. Cereal Sci. 21 (3), 215-230.

Giannone, V., Lauro, M.R., Spina, A., Pasqualone, A., Auditore, L., Puglisi, I., Puglisi, G. 2016. A novel $\alpha$-amylase-lipase formulation as anti-staling agent in durum wheat bread. LWT-Food Sci. Technol. 65, 381-389.

Goesaert, H., Slade, L., Levine, H., Delcour, J.A., 2009. Amylases and bread firming-an integrated view. J. Cereal Sci. 50 (3), 345-352.

Gómez, M., Del Real, S., Rosell, C.M., Ronda, F., Blanco, C.A., Caballero, P.A., 2004 Functionality of different emulsifiers on the performance of breadmaking and wheat bread quality. Eur. Food Res. Technol. 219 (2), 145-150.

Gomes-Ruffi, C.R., da Cunha, R.H., Almeida, E.L., Chang, Y.K., Steel, C.J., 2012. Effect of the emulsifier sodium stearoyl lactylate and of the enzyme maltogenic amylase on the quality of pan bread during storage. LWT-Food Sci. Technol. 49 (1), 96-101.

Grenier, D., Le Ray, D., Lucas, T., 2010. Combining local pressure and temperature measurements during bread baking: insights into crust properties and alveolar structure of crumb. J. Cereal Sci. 52 (1), 1-8.

Haros, M., Rosell, C.M., Benedito, C., 2002. Effect of different carbohydrases on fresh bread texture and bread staling. Eur. Food Res. Technol. 215 (5), 425-430.

Hemalatha, M.S., Rao, U.P., Leelavathi, K., Salimath, P.V., 2010. Influence of amylases and xylanase on chemical, sensory, amylograph properties and microstructure of chapati. LWT-Food Sci. Technol. 43 (9), 1394-1402.

Jha, P.K., Chevallier, S., Cheio, J., Rawson, A., Le-Bail, A., 2017. Impact of resting time between mixing and shaping on the dough porosity and final cell distribution in sandwich bread. J. Food Eng. 194, 15-23.

Li, X., Li, D., Tian, H., Park, K.H., 2014. Reducing retrogradation of gelatinized rice starch and rice meal under low temperature storage by addition of extremely thermostable maltogenic amylase during their cooking. Food Res. Int. 62, $1134-1140$.

Mathewson, P.R., 1998. Application of enzymes to baked products. In: Mathewson, P.R. (Ed.), Enzymes. Eagan Press, Minnesota, pp. 49-58.

Mohd Jusoh, Y.M., Chin, N.L., Yusof, Y.A., Rahman, R.A., 2009. Bread crust thickness measurement using digital imaging and L a b colour system. J. Food Eng. 94 (3), 366-371.

Onyango, C., Mutungi, C., Unbehend, G., Lindhauer, M.G., 2010. Rheological and baking characteristics of batter and bread prepared from pregelatinized cassava starch and sorghum and modified using microbial transglutaminase. J. Food Eng. 97 (4), 465-470.

Ponce-García, N., Ramírez-Wong, B., Torres-Chávez, P.I., Figueroa-Cárdenas, J.D.D., Serna-Saldívar, S.O., Cortez-Rocha, M.O., Escalante-Aburto, A., 2017. Evaluation of visco-elastic properties of conditioned wheat kernels and their doughs using a compression test under small strain. J. Sci. Food Agric. 97 (4), 1235-1243.

Primo-Martín, C., Van de Pijpekamp, A., Van Vliet, T., De Jongh, H.H.J., Plijter, J.J. Hamer, R.J., 2006. The role of the gluten network in the crispness of bread crust. J. Cereal Sci. 43 (3), 342-352.

Purlis, E., Salvadori, V.O., 2009. Modelling the browning of bread during baking. 
Food Res. Int. 42 (7), 865-870.

Schoenlechner, R., Szatmari, M., Bagdi, A., Tömösközi, S., 2013. Optimization of bread quality produced from wheat and proso millet (Panicum miliaceum L.) by adding emulsifiers, transglutaminase and xylanase. LWT-Food Sci. Technol. 51 (1), 361-366.

Tlapale-Valdivia, A.D., Chanona-Pérez, J., Mora-Escobedo, R., Farrera-Rebollo, R.R., Gutiérrez-López, G.F., Calderón-Domínguez, G., 2010. Dough and crumb grain changes during mixing and fermentation and their relation with extension properties and bread quality of yeasted sweet dough. Int. J. Food Sci. Technol. 45
(3), 530-539.

van Oort, M., 2010. Enzymes in bread making. In: Whitehurst, R.J., van Oort, M. (Eds.), Enzymes in Food Technology. Wiley-Blackwell, New Jersey, pp. 103-143. Zghal, M.C., Scanlon, M.G., Sapirstein, H.D., 2001. Effects of flour strength, baking absorption, and processing conditions on the structure and mechanical properties of bread crumb. Cereal Chem. 78 (1), 1-7.

Zhang, J., Datta, A.K., 2006. Mathematical modeling of bread baking process. J. Food Eng. 75 (1), 78-89. 